\title{
PENGARUH KUALITAS PELAYANAN DAN KUALITAS PRODUK TABUNGAN iB HASANAH TERHADAP KEPUASAN NASABAH PADA PT BANK BNI SYARIAH KANTOR CABANG MEDAN
}

\section{EFFECT OF SERVICE QUALITY AND IB HASANAH SAVINGS PRODUCT QUALITY TOWARDS CUSTOMER SATISFACTION IN PT BANK BNI SYARIAH KANTOR CABANG MEDAN}

\author{
Raudhatul Zahrah Rahfizah'1a, Supaino², Ahmad Kholil ${ }^{3}$ \\ 1Program Studi Keuangan dan Perbankan Syariah Politeknik Negeri Medan \\ 2Program Studi Keuangan dan Perbankan Syariah Politeknik Negeri Medan \\ ${ }^{3}$ Program Studi Keuangan dan Perbankan Syariah Politeknik Negeri Medan \\ aKoresponden: Raudhatul Zahrah Rahfizah, Email: zahrahrahfizah@gmail.com
}

\begin{abstract}
This research was conducted to determine the effect of service quality and iB Hasanah savings product quality on customer satisfaction at PT Bank BNI Syariah Kantor Cabang Medan. The dependent variable in this study is the customer satisfaction, while the independent variable consists of service quality and iB Hasanah savings product quality. The sample in this study 100 respondents. The the research method used in this study is multiple linear regression analysis, partial test $(\mathrm{t})$ and simultaneous test $(\mathrm{F})$ with the help of SPSS 22 program software. The results of the partial test $(\mathrm{t})$ show that each independent variable has a positive and significant effect on the variable dependent because the significance 0,000 . The results of the statistical $t$ test showed thar service quality had no positive and insignificant effect with a significance level of 0,935 and iB Hasanah savings product quality has a positive and significant effect with a significance level of 0,000.
\end{abstract}

Keywords: Service Quality, iB Hasanah Savings Product, Customer Satisfaction

\section{ABSTRAK}

Penelitian ini dilakukan untuk mengetahui pengaruh kualitas pelayanan dan kualitas produk tabungan iB Hasanah terhadap kepuasan nasabah pada PT Bank BNI Syariah Kantor Cabang Medan. Variabel dependen dalam penelitian ini adalah kepuasan nasabah sedangkan variabel independen terdiri dari kualitas pelayanan dan kualitas produk tabungan iB Hasanah. Sampel yang digunakan dalam penelitian ini sebanyak 100 orang Penelitian ini menggunakan kuisioner sebagai data primer kemudian hasil datanya dianalisis menggunakan regresi berganda dengan melakukan uji simultan (F), uji determinasi, dan uji parsial $(\mathrm{t})$ dengan tingkat signifikan sebesar 5 persen $(\alpha=0,05)$ yang diolah dengan bantuan alat SPSS 22. Hasil penelitian ini menunjukkan adanya pengaruh positif dan signifikan secara simultan antara kualitas pelayanan dan kualitas produk tabungan iB Hasanah terhadap kepuasan nasabah pada PT Bank BNI Syariah Kantor Cabang Medan yang dilihat melalui uji statistik F dengan nilai signifikansi sebesar 0,000. Hasil uji statistik t menunjukkan bahwa kualitas pelayanan tidak berpengaruh positif dan tidak signifikan dengan tingkat signifikansi sebesar 0,935 dan kualitas produk tabungan iB Hasanah berpengaruh positif dan signifikan dengan tingkat signifikansi sebesar 0,000.

Kata Kunci: Kualitas Pelayanan, Kualitas Produk Tabungan iB Hasanah, Kepuasan Nasabah 
Raudhatul Zahrah Rahfizah, 2020. Pengaruh Kualitas Pelayanan dan Kualitas Produk Tabungan iB Hasanah terhadap Kepuasan Nasabah pada PT Bank BNI Syariah Kantor Cabang Medan. Jurnal Nisbah 6 (1): 23-29.

\section{PENDAHULUAN}

Perbankan syariah saat ini banyak diminati oleh masyarakat. Selain diatur dalam undang-undang, bank syariah juga harus menerapkan prinsip-prinsip syariah yang ditetapkan dalam Al-Qur'an dan Hadits dalam melakukan kegiatan usahanya. Usaha pembentukan sistem perbankan syariah didasari oleh larangan agama untuk menggunakan sistem yang merujuk pada praktek riba, baik dalam hutang piutang dengan bunga ataupun larangan investasi yang sduah jelas haram dari dzat nya maupun selain dzatnya. Hal tersebut tidak dapat dijamin oleh sistem perbankan konvensional (Febriana, 2016:01).

Dalam jangka waktu yang panjang, perusahaan tetap bertahan dalam menghadapi persaingan bisnis yang global adalah perusahaan yang terus melakukan perbaikan dalam kegiatan pelayanan, operasional jasa atau inovasi produk untuk selalu meningkatkan kualitas (Rahmayanti, 2016:3). Menurut Kotler dalam Kasmir (2012:263), kepuasan nasabah adalah penilaian dari nasabah atas produk dan jasa yang digunakan kemudian dibandingkan dengan harapan sebelum penggunaannya. Dalam menjalankan usahanya PT Bank BNI Syariah Kantor Cabang Medan meningkatkan kepuasan nasabah dengan memberikan kualitas layanan dan kualitas produk yang baik.

Landasan utama perbankan syariah dalam menjalankan usahanya yaitu dengan menerapkan pola bagi hasil, baik produk pendanaan, produk pembiayaan maupun produk lainnya. PT Bank BNI Syariah Kantor Cabang Medan saat ini memiliki beberapa produk unggulan yang dapat bersaing baik dari segi teknologi maupun pendekatan kepada masyarakat. Adapun produk tabungan memiliki jumlah nasabah terbesar dan paling diandalkan adalah Tabungan iB Hasanah. Tabungan iB Hasanah merupakan produk simpanan dana dari Bank Indonesia yang pengelolaanya sesuai dengan prinsip syariah. Produk Tabungan iB Hasanah dapat bermanfaat untuk wadah investasi yang murni sesuai syariah, nasabah dapat menyetorkan dan melakukan penarikan tunai dengan mudah, bank juga dapat menjaga amanah dari nasabah sesuai dengan akad yang digunakan.

Seluruh bank melakukan invoasi dalam situasi persaingan perbankan, hal ini ditujukan agar menarik minat calon nasabah dan menjaga nasabah yang sudah ada. Usaha tersebut dapat dikatakan berhasil apabila perbankan mampu memberikan kualitas pelayanan yang baik dan prima. Pelayanan yang berkualitas merupakan suatu hal yang mutlak perlu dilakukan oleh lembaga perbankan. Kualitas layanan mendorong nasabah untuk memiliki komitmen terhadap produk dan layanan suatu perbankan sehingga berpengaruh pada peningkatan suatu produk. Adanya pelayanan yang berkualitas dalam suatu perusahaan akan menciptakan kepuasan bagi para konsumen. Apabila konsumen merasa puas atas pelayanan yang diberikan oleh perusahaan, maka konsumen akan loyal terhadap perusahaan tersebut (Wahab, 2017:01).

Dalam menciptakan kepuasan nasabah, perbankan harus dapat meningkatkan kualitas layanan maupun keunggulan produknya. Sama seperti bank syariah lain, PT Bank BNI Syariah Kantor Cabang Medan melayani berbagai macam kebutuhan nasabah dan memberikan kenyamanan bagi nasabah. Menurut Kotler dalam Kasmir (2012:263) nasabah memang harus diberikan pelayanan yang baik dan cepat sesuai dengan transaksi bank. Apabila pelayan 
yang diterimanya kurang cepat dan tanggap, maka mereka akan meninggalkan perusahaan dan menjadi nasabah di perusahaan pesaing.

\section{MATERI DAN METODE}

Menurut Fandy Tjiptono (2005:29) fokus kualitas pelayanan adalah upaya pemenuhan kebutuhan dan keinginan konsumen serta penyampaian yang tepat guna mengimbangi ekspektasi pelanggan. Menurut Othman dan Owen (2001:10), dimensi kualitas layanan dapat diukur dengan enam dimensi yaitu sebagai berikut:

\section{Reliability}

Reliability (kehandalan) dinilai dari kemampuan bank dalam memberikan layanan yang konsisten, konsisten dengan yang dijanjikan kepada nasabah, misalnya dalam hal pemenuhan jam operasim konsisten pegawai dalam melayani, penyediaan produk yang sesuai dengan janji, dan lain-lain.

2. Responsiveness

Responsiveness (ketanggapan) adalah kesedian bank untuk memberikan tanggapan secara cepat kepada nasabah.

\section{Assurance}

Assurance (jaminan) adalah kemampuan penyedia jasa dalam hal ini perbankan Islam untuk meyakinkan kepada nasabahnya.

4. Empathy

Empathy (empati) adalah kemampuan bank dan juga pegawainya dalam mengerti kebutuhan dan keinginan nasabah.

5. Tangible

Tangible (keberwujudan) adalah berkenaan dengan hal-hal fisik yang dapat dengan mudah dilihat oleh nasabah.

6. Compliance

Compliance (kepatuhan) adalah tingkat kepatuhan dari bank dalam memberikan layanan dalam menjalankan proses bisnis berdasarkan prinsip syariah.

Menurut Tjiptono (1999:95) produk adalah sesuatu yang ditawarkan ke pasar sebagai usaha untuk mencapai tujuan organisasi dengan terpenuhinya kebutuhan dan keinginan konsumen. Mengingat semakin banyak pesaing, perusahaan berlomba-lomba untuk mengeluarkan produk agar menarik minat konsumen. Produk yang akan dikeluarkan adalah produk unggulan dari perusahaan tersebut.

Menurut Kartajaya dan Sula dalam Wasiah (2017:13) bagi perusahaan yang berbasis syariah, kualitas produk harus berdasarkan dengan nilai kejujuran dan keadilan. Kualitas produk harus sesuai dengan yang ditawarkan, perusahaan pun tidak boleh meyembunyikan kecacatan dari produk yang mereka tawarkan.

Kepuasan merupakan respon dari nasabah dikarenakan adanya kesesuaian antara harapan dengan kinerja perbankan yang diterima. Jika kesesuaian didapatkan melebihi ekspektasi nasabah, maka itulah puncak dari kepuasan. Namun, jika yang nasabah dapatkan adalah ketidaksesuaian maka nasabah akan merasa tidak puas dan kecewa. Kepuasan sangat berpengaruh demi kesetiaan nasabah terhadap bank. Semakin tinggi tingkat kepuasan yang nasabah dapatkan, maka akan semakin lama nasabah bertahan dan loyal kepada bank tersebut.

\section{Metode Penelitian}

Penelitian ini merupakan jenis penelitian kuantitatif. Data yang digunakan pada penelitian ini adalah data primer dan sekunder. Data primer diperoleh dari kuisioner yang diberikan kepada nasabah tabungan iB Hasanah pada PT Bank BNI Syariah Kantor Cabang Medan, sedangkan data sekunder diperoleh dari buku-buku, internet dan bahan acuan lainnya yang berhubungan dengan konsep penelitian yang akan dilakukan terkait dengan kualitas pelayanan, kualitas produk tabungan iB Hasanah, kepuasan nasabah. 
Data digunakan merupakan data primer diperoleh melalui kuisioner yang disebarkan kepada 100 responden. Penentuan sample dilakukan dengan menggunakan rumus slovin. Penelitian ini akan menggunakan teknik pengambilan sampel dengan cara teknik sampling insidental. Penelitian ini menggunakan variable independen kualitas pelayanan (X1), kualitas produk tabungan iB Hasanah (X2). Juga Variabel dependen dari penelitian ini adalah kepuasan nasabah pada PT Bank BNI Syariah Kantor Cabang Medan.

Teknik analisis data adalah teknik yang digunakan untuk mengelola hasil penelitian guna memperoleh kesimpulan. Adapun teknik analisis data yang digunakan adalah analisis regresi linear berganda dengan menggunakan program SPSS 24.

\section{HASIL DAN PEMBAHASAN}

\section{Uji Asumsi Klasik \\ Uji Normalitas}

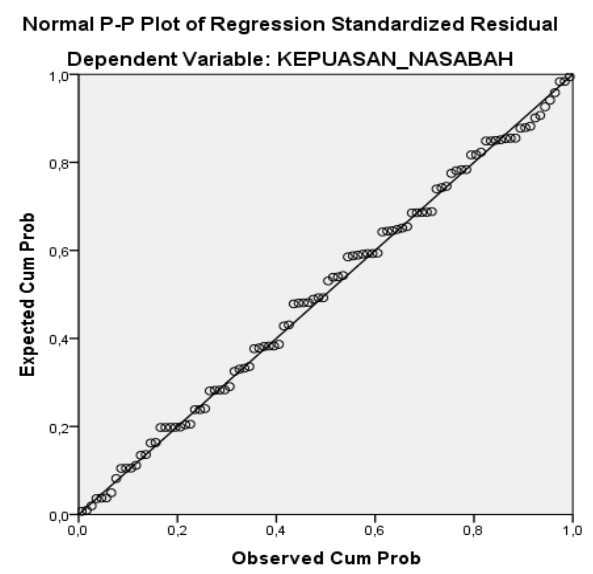

Gambar 1 Grafik P-Plot

Dari gambar 1 di atas menunjukkan pola grafik P-Plot yang normal, terlihat dari titik distribusi dan menyebar disekitar garis diagonal dan penyebarannya mengikuti garis diagonal. Hal ini menunjukkan bahwa data berdistribusi normal dan asumsi normalitas terpenuhi.

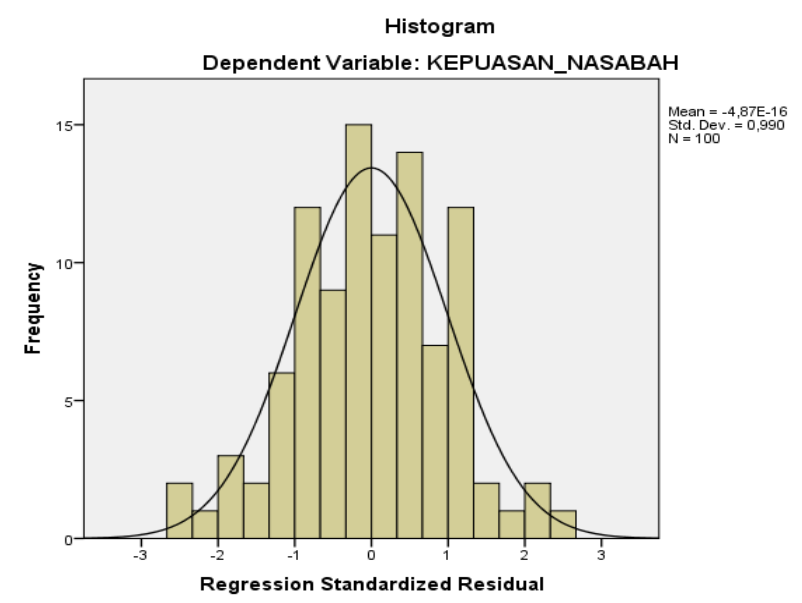

Gambar 2 Histogram

Berdasarkan gambar 2 di atas dapat dilihat bahwa kurva membentuk seperti lonceng, maka nilai residual tersebut dinyatakan normal atau berdistribusi normal.

\section{Uji Multikolinearitas}

Untuk menguji multikolinearitas dapat dilihat dari nilai Tolerance dan Variance Inflation Factor (VIF). Suatu model regresi dikatakan terbebas dari masalah multikolinearitas apabila nilai Tolerance > 0,01 atau nilai VIF < 10 (Ghozali, 2013: 105). Hasil uji multikolinearitas pada penelitian ini menunjukkan bahwa nilai VIF untuk variabel independen tidak ada yang lebih besar dari 10, sedangkan untuk nilai Tolerancenya variabel independen lebih besar dari 0,10. Maka dapat disimpulkan bahwa tidak terjadi multikolinearitas pada variabel independen (bebas) tersebut.

\section{Uji Heteroskedastisitas}

Uji heteroskedastisitas bertujuan untuk menguji apakah dalam model regresi terjadi ketidaksamaan variance dari residual satu pengamatan ke pengamatan yang lain. Pengujian heteroskedastisitas dilakukan berdasarkan analisi grafik scatter plot. Berdasarkan hasil pengolahan data diketahui bahwa nilai signifikan masing-masing variabel kualitas pelayanan sebesar 0,926, variabel kualitas produk tabungan iB Hasanah sebesar 0,758. Karena semua nilai variabel bebas $>0,05$ maka 
disimpulkan bahwa model regresi ini tidak terjadi heteroskedastisitas.

\section{Hasil Analisis Karakteristik Responden}

1) Data Jenis Kelamin Responden

Berdasarkan data yang diperoleh peneliti diketahui bahwa 47 responden $(47 \%)$ berjenis kelamin pria dan 53 responden (53\%) berjenis kelamin wanita. Artinya mayoritas responden pada penelitian ini berjenis kelamin wanita yaitu $53 \%$.

\section{2) Data Usia Responden}

Berdasarkan perolehan data pada penelitian ini diketahui bahwa karakteristik responden nasabah tabungan iB Hasanah pada PT Bank BNI Syariah Kantor Cabang Medan yang berusia $<20$ tahun sebanyak 18 orang (18\%), yang berusia $>50$ tahun sebanyak 6 orang $(6 \%)$, yang berusia 20-35 tahun sebanyak 59 orang (59\%), dan yang berusia 30-50 tahun sebanyak 17 orang (17\%).

\section{3) Data Agama Responden}

Data pada penelitian menujukkan bahwa karakteristik responden nasabah tabungan iB Hasanah pada PT Bank BNI Syariah Kantor Cabang Medan yang beragama Islam sebanyak 88 orang (88\%), dan yang beragama kristen sebanyak 12 orang (12\%).

4) Data Penghasilan Responden

Berdasarkan data yang didapatkan peneliti diketahui bahwa karakteristik responden nasabah tabungan iB Hasanah pada PT Bank BNI Syariah Kantor Cabang Medan yang memiliki penghasilan $>$ Rp.5.000.000 sebanyak 7 orang (7\%), yang memiliki penghasilan Rp.1.000.000-Rp.2.500.000 sebanyak 26 orang (26\%), yang memiliki penghasilan Rp.2500.000Rp.5.000.000 sebanyak 43 orang (43\%), dan yang memiliki penghasilan Rp.500.000-
Rp.1.000.000 sebanyak 24 orang (24\%).

\section{Hasil Analisis Regresi Linear Berganda}

Tabel 1 Hasil Uji Analisis Regresi Linear Berganda

\begin{tabular}{|l|c|r|r|r|}
\hline \multicolumn{1}{|c|}{ Model } & B & $\begin{array}{c}\text { Standa } \\
\text { r Error }\end{array}$ & T & Sig. \\
\hline (Constant & 13.31 & 2.646 & 5.03 & 0.00 \\
) & 6 & & 3 & 0 \\
\hline Kualitas & -0.004 & 0.044 & - & 0.93 \\
Pelayana & & & 0.08 & 5 \\
n (X1), & & & 2 & \\
\hline Kualitas & 0.342 & 0.079 & 4.30 & 0.00 \\
Produk & & & 3 & 0 \\
Tabungan & & & & \\
iB & & & & \\
Hasanah & & & & \\
(X2), & & & & \\
\hline
\end{tabular}

Berdasarkan hasil pengolahan data pada tabel 1 di atas maka diperoleh persamaan regresi linear sebagai berikut:

$$
\begin{gathered}
Y=13,316-0,004 X_{1}+0,342 X_{2} \\
\text { Atau }
\end{gathered}
$$

Kepuasan Nasabah= 13,316 - 0,004 KP + $0,342 \mathrm{kpr}$

Dari persamaan regresi di atas dapat dinyatakan nilai koefisien regresinya sebagai berikut:

Apabila tingkat signifikansi lebih kecil dari 0,05 dan $\mathrm{F}$ hitung lebih besar dari $\mathrm{F}$ tabel, maka variabel independen berpengaruh secara simultan terhadap variabel dependen. Berdasarkan hasil penelitian ini diperoleh tingkat signifikansi variabel sebesar 0,000 yang artinya lebih kecil dari 0,05 $(0,000<0,05)$ dan $F$ hitung sebesar 9,579 lebih besar dibandingkan F tabel 3,09 $(9,579>3,09)$, maka dapat disimpulkan bahwa variabel kualitas pelayanan dan kualitas produk tabungan iB Hasanah secara simultan berpengaruh signifikan terhadap kepuasan nasabah pada PT Bank BNI Syariah Kantor Cabang Medan.

\section{Uji t (Parsial)}

Nilai uji t variabel kualitas pelayanan (X1) memiliki nilai signifikan 0,935 lebih besar dari $0,05 \quad(-0,935>0,05)$ maka $\mathrm{H}_{01}$ diterima yang artinya variabel Nilai kualitas pelayanan tidak mempunyai pengaruh signifikan terhadap kepuasan 
nasabah pada PT Bank BNI Syariah Kantor Cabang Medan.

Berdasarkan hasil pengolahan uji $t$ diketahui bahwa variabel kualitas produk tabungan iB hasanah (X2) memiliki nilai signifikansi 0,000 lebih kecil dari 0,05 $(0,000<0,05)$. Juga memiliki nilai thitung variabel kualitas produk tabungan iB hasanah sebesar 4,303 sedangkan nilai $t_{\text {tabel }}$ sebesar 1,984. Hal ini menunjukkan bahwa terdapat pengaruh yang signifikan antara Kualitas Produk Tabungan iB Hasanah terhadap variabel kepuasan nasabah.

\section{Uji F}

Uji simultan (uji F) pada prinsipnya bertujuan untuk mengetahui pengaruh dari dua variabel independen atau lebih secara simultan (bersamasama) terhadap variabel dependen. Untuk mengetahui pengaruh dari variabel Iklan, sosiliasasi, dan rekomendasi terhadap minat masyarakat muslim menabung di bank syariah, maka dapat dijelaskan sebagai berikut:

Tabel 2 Hasil Uji F (Simultan)

\begin{tabular}{|l|r|r|r|c|}
\hline Model & \multicolumn{1}{|c|}{$\mathrm{df}$} & $\begin{array}{c}\text { Mean } \\
\text { Square }\end{array}$ & $\mathrm{F}$ & Sig. \\
\hline Regression & 2 & 58.486 & 9.579 & $.000^{\mathrm{b}}$ \\
\hline Residual & 97 & 6.106 & & \\
\hline Total & 99 & & & \\
\hline
\end{tabular}

Dari Tabel 2 diketahui bahwa nilai $\mathrm{F}$ diperoleh sebesar 9.579. Tabel distribusi F dicari pada tingkat kepercayaan $\alpha=5 \%$, df1 (k-1) atau (3-1) = 2 dan df2 (n-k) atau 100-3 = 97 maka diperoleh nilai $\mathrm{F}$ tabel sebesar 3,09. F hitung $>\mathrm{F}$ tabel yaitu 9,579 > 3,09 maka $\mathrm{H}_{03}$ ditolak dan $\mathrm{H}_{\mathrm{a} 3}$ diterima, sehingga dapat disimpulkan bahwa variabel kualitas pelayanan, dan kualitas produk tabungan iB Hasanah berpengaruh signifikan terhadap kepuasan nasabah pada PT Bank BNI Syariah Kantor Cabang Medan.

\section{Koefisien Determinasi $\left(R^{2}\right)$}

Koefisien determinasi $\left(R^{2}\right)$ pada intinya mengukur seberapa jauh kemampuan model dalam menerangkan variasi variabel dependen. Nilai koefisien determinasi adalah antara nol dan satu. Nilai $\mathrm{R}^{2}$ yang kecil berarti kemampuan variabel-variabel independen dalam menjelaskan variasi variabel dependen amat terbatas. Nilai yang mendekati satu berarti variabel-variabel independen memberikan hampir semua informasi yang dibutuhkan untuk memprediksi variasi variabel dependen (Ghozali, 2017:95).

Hasil uji koefisien determinasi sebagai berikut:

Tabel 3 Uji Koefisien Determinasi $\left(\mathrm{R}^{2}\right)$

\begin{tabular}{|l|l|r|r|}
\hline Model & $\mathrm{R}$ & R Square & $\begin{array}{c}\text { Adjusted R } \\
\text { Square }\end{array}$ \\
\hline 1 &, $406^{\mathrm{a}}$ & .165 & .148 \\
\hline
\end{tabular}

Dari tabel 3 dapat kita lihat bahwa koefisien determinasi $\left(\mathrm{R}^{2}\right)$ sebesar 0,165 menunjukkan bahwa proporsi variabel independen menjelaskan atau mempengaruhi variabel dependen sebesar 16,5\%, sedangkan sisanya sebesar 83,5\% (100\% - 16,5\%) dijelaskan atau dipengaruhi oleh variabel lain yang tidak diteliti lain yang tidak dimasukkan dalam model penelitian ini. Jadi terdapat banyak variabel-variabel yang dapat mempengaruhi kepuasan nasabah pada PT Bank BNI Syariah Kantor Cabang Medan.

\section{KESIMPULAN DAN IMPLIKASI}

Berdasarkan hasil penelitian dan pembahasan yang telah diuraikan maka dapat disimpulkan bahwa Nilai konstanta dari variabel kualitas pelayanan yaitu 13.316. Variabel kualitas pelayanan dan kualitas produk tabungan iB Hasanah secara simultan mempunyai pengaruh yang signifikan dan positif terhadap kepuasan nasabah pada PT Bank BNI Syariah Kantor Cabang Medan dengan nilai signifikansi sebesar $0,000<0,05$.

Bagi peneliti selanjutnya dapat meneliti dengan variabel-variabel lain diluar variabel yang telah diteliti ini agar memperoleh hasil yang lebih berpengaruh terhadap kepuasan nasabah 
pada PT Bank BNI Syariah Kantor Cabang Medan.

\section{DAFTAR PUSTAKA}

Ghozali, Imam. 2015. Aplikasi Analisis Multi Variete. Semarang: Badan Penerbit Universitas Diponegoro.

Kasmir. 2012. Manajemen Perbankan. Jakarta: Kencana.

Lupiyoadi, Rambat. 2001. Manajemen Pemasaran Jasa. Jakarta: Salemba Empat

Muhammad. 2015. Manajemen Dasar Bank Syariah, cetakan kedua. Jakarta: Rajawali Pers.

Noor, Juliansyah. 2012. Metodologi Penelitian: Skripsi, Tesis, Disertasi, dan Karya Ilmiah. Jakarta: Kencana.

Othman, A.Q., dan Owen, L., 2001, Developing an Instrument to Measure Customer Service Quality (SQ) in Islamic Banking International Journal of Islamic Financial Services, Vol. 3, April and June.

Rianty, Adella. 2017. Pengaruh Kualitas Pelayanan Dan Bagi Hasil
Terhadap Kepuasan Nasabah Tabungan Mudharabah Studi Kasus Pada PT. Bank Syariah Mandiri di Wilayah Tangerang Selatan. Universitas Islam Negeri Syarif Hidayatullah Jakarta.

Sugiyono. 2010. Metode Penelitian Pendidikan Pendekatan Kuantitatif, Kualitatif Dan R\&D. Bandung: Alfabeta.

Sugiyono. 2013. Metode Penelitian Kuantitatif, Kualitatif, dan R\&D. Bandung: Alfabeta.

Sugiyono. 2015. Metode Penelitian Kuantitatif, Kualitatif, dan R\&D. Cetakan ke 22. Bandung: CV Alfa Beta

Sugiyono. 2016. Metode Penelitian Kuantitatif, Kualitatif, dan Kombinasi (Mix Methods). Bandung: Alfabeta.

Sugiyono. 2017. Metode Penelitian Kuantitatif, Kualitatif, dan R\&D. Bandung: Alfabeta.

Wijaya, Tony. 2011. Manajemen Kualitas Jasa. Jakarta: Indeks. www.topbrandaward.com 